\title{
A Horizontal Three-Electrode Structure for Zinc-Air Batteries with Long-Term Cycle Life and High Performance
}

\author{
Weichen Hong ${ }^{1}$, Hui Li $^{2}$, Baoguo Wang ${ }^{1, *}$ \\ ${ }^{1}$ Department of Chemical Engineering, Tsinghua University, Beijing 100084, China \\ ${ }^{2}$ South University of Science and Technology of China, Shenzhen, Guangdong, 518055, China \\ *E-mail: bgwang@tsinghua.edu.cn.
}

doi: $10.20964 / 110384$

Received: 19 January 2016 / Accepted: 25 February 2016 / Published: 1 April 2016

Limited cycle life is a main reason preventing the large-scale application of electrically rechargeable zinc-air batteries. With the aim of increasing cycle life, a novel three-electrode zinc-air battery in a sandwich arrangement was designed and fabricated. The cycle life was evaluated by charge-discharge cycling tests with 100 cycles at high operational current density $\left(40 \mathrm{~mA} \mathrm{~cm}^{-2}\right.$ and $80 \mathrm{~mA} \mathrm{~cm}^{-2}$ for charging and discharging, respectively) for performance testing. A maximum power density of 105 $\mathrm{mW} \mathrm{cm}{ }^{-2}$ was achieved at current density of $150 \mathrm{~mA} \mathrm{~cm}^{-2}$. The average columbic efficiency, depth of discharge and energy efficiency were $90 \%, 73 \%$ and $42 \%$, respectively. A longer cycling test for 1000 cycles approximately $1917 \mathrm{~h}$ cycling duration at a current density of $20 \mathrm{~mA} \mathrm{~cm}$. was also achieved and voltage decay for charging and discharging was $13 \%$ and $12 \%$, respectively. The results demonstrate that a horizontal tri-electrode structure for zinc-air batteries is advantageous for achieving increased cycle life while exhibiting high power density, high depth of discharge and excellent charge-discharge cycling performance, which provide promising applications of zinc-air batteries for electric vehicle and grid-scale energy storage.

Keywords: Zinc-air batteries, Three-electrode, Horizontal placement, Cycle life

\section{$\underline{\text { FULL TEXT }}$}

(C) 2016 The Authors. Published by ESG (www.electrochemsci.org). This article is an open access article distributed under the terms and conditions of the Creative Commons Attribution license (http://creativecommons.org/licenses/by/4.0/). 